\title{
Intertextualidad en la serie Bolívar, una lucha admirable y el libro Bolívar, libertador y enemigo número 1 del Perú
}

\author{
Intertextuality in the series Bolivar, an admirable struggle and the book Bolivar, liberator and \\ enemy number 1 of Peru
}

Mario Buenaventura Castillo Hilario ' (D) (8:)

\section{Cómo citar}

Castillo, M. (2021). La serie Bolívar, una lucha admirable y el libro Bolívar, libertador y enemigo número 1 del Perú. Una lectura intertextual a propósito del Bicentenario. Socialium, 5(2), 72-98. https://doi.org/10.26490/uncp.sl.2021.5.2.937

${ }^{1}$ Magíster en Comunicación Social con mención en Investigación en Comunicación, Licenciado en Ciencias de la Comunicación. Universidad Nacional Agraria La Molina, Lima, Perú. mcastillo@lamolina.edu.pe

Arbitrado por pares ciegos Recibido: 09/05/2021 Aceptado: $26 / 06 / 2021$

\section{RESUMEN}

El objetivo de esta investigación fue identificar las relaciones intertextuales entre la serie televisiva Bolívar, una lucha admirable y la biografía escrita Bolívar, libertador y enemigo número 1 del Perú. Para ello, se optó por un enfoque cualitativo y un diseño interpretativo. Se leyeron e interpretaron textos para identificar en ellos las relaciones intertextuales. Se encontraron las siguientes relaciones intertextuales: citas y alusiones. Existen semejanzas en la presentación global de Simón Bolívar en relación con el Perú; la Batalla de Pichincha; la entrada de Bolívar a las ciudades; las situaciones previas y el encuentro en Guayaquil entre Simón Bolívar y San Martín; los acontecimientos previos y la llegada de Bolívar al Perú; las batallas de Junín y Ayacucho; la Constitución vitalicia; y los últimos días de Bolívar en Perú y su salida. La serie reafirma la idea de que la independencia del Perú fue "concedida".

Palabras clave: intertextualidad; intertexto; subtexto; serie; Bolívar; independencia del Perú.

\section{ABSTRACT}

The objective of this research was to identify the intertextual relationships between the television series Bolivar, an admirable struggle and the written biography Bolivar, liberator and enemy number 1 of Peru. For this, a qualitative approach and an interpretive design were chosen. Texts were read and interpreted to identify intertextual relationships in them. The following intertextual relationships were found: citations and allusions. There are similarities in Simon Bolivar's global presentation in relation to Peru; the battle of Pichincha; the entrance of Bolivar to the cities; the situations prior and the meeting in Guayaquil between Simon Bolivar and San Martin; the previous events and Bolivar's arrival in Peru; the battles of Junin and Ayacucho; the lifetime Constitution; and the last days of Bolivar in Peru and his departure. The series reaffirms the idea that the independence of Peru was "granted".

Keywords: intertextuality; intertext; subtext; series; Bolivar; independence of Peru. 


\section{Introducción}

La cultura de masas siempre generó discusiones entre acusadores y defensores, entre apocalípticos e integrados (Eco, 2013b). Bolívar, una lucha admirable, serie televisiva basada en la vida del Libertador Simón Bolívar, no ha sido la excepción. La historiadora venezolana Inés Quintero ha afirmado:

Desde que comenzó a transmitirse la serie Bolívar en Netflix, numerosas personas me han llamado o me han consultado acerca de la veracidad histórica de muchos de los sucesos que allí se narran. La repuesta ha sido un contundente NO. La serie Bolívar NO está ceñida al rigor histórico. Es cuento, no es historia [...] lo que sí puedo garantizarles es que, cuando terminen de ver esta serietelenovela, no será mucha historia la que habrán aprendido, sino todo lo contrario. Yo, por mi parte, no pienso dedicarle ni un minuto más de mi tiempo libre (Quintero, 2019).

Por el contrario, la creadora de la serie Juana Uribe manifestó que leyó muchos libros de historia y consultó a los historiadores para darle coherencia histórica y credibilidad a su obra, así como para interpretar los hechos y ponerlos en contexto. Claro, también especuló y presentó lo que pudo ser, situaciones que pudieron haber sucedido. En ese sentido, la serie no estaría reñida con la historia y, más bien, podría enseñarla o estimular su conocimiento. Juana Uribe contó:

Una de las mayores satisfacciones es oír a la gente que me dice: "Me puse a ver la serie y me despertó tanta curiosidad, que me compré las biografías y empecé a leer". Eso ya es una victoria, porque no buscamos imponer una visión, sino abrir las mentes a un diálogo sobre las facetas de Bolívar. Me encantaría que los profesores vean la serie con los alumnos, investiguen y digan en qué están de acuerdo o no. Que aprovechen el lenguaje audiovisual como herramienta pedagógica. Por Netflix Simón Bolívar y las batallas han estado entre los diez más buscados en Wikipedia en el mundo. La gente verifica a ver qué cambiamos (Padilla, 2019).

Esta investigación no pretende hacer una defensa de la serie Bolívar, una lucha admirable como documento histórico ni una crítica, sino una lectura intertextual, un ejercicio de la competencia intertextual. Para ello, se asume la posición del televidente que busca aprender de lo que le ofrece la televisión.

Como la intertextualidad puede ser infinita, nos limitamos a identificar las relaciones intertextuales que son de interés para el Perú, a propósito de su Bicentenario (1821-2021). Así, proponemos responder: ¿cuáles son las relaciones intertextuales entre la serie Bolívar, una lucha admirable y el libro Bolívar, libertador y enemigo número 1 del Perú? 
El problema planteado se puede abordar desde la semiótica del texto y desde la teoría de la historia como narración. Así, es pertinente la teoría ofrecida por los autores que han reflexionado sobre los textos y la teoría formalista de la historia propuesta por Hayden White.

\section{La intertextualidad}

Desde la semiótica de la cultura, se define el texto en sentido amplio y no únicamente como lo lingüístico. Una danza, un cuadro, una pieza musical o una representación teatral son textos (Martínez, 2001, p. 20). Se consideran como textos, también, a los productos audiovisuales: filmes, telenovelas, series, documentales.

Gerard Genette (1989) ha propuesto una teoría sobre la transtextualidad. En sentido amplio, sostiene que la transtextualidad o trascendencia textual es "todo lo que pone al texto en relación, manifiesta o secreta, con otros textos" (pp.9-10). Existen cinco tipos: intertextualidad, paratextualidad, metatextualidad, architextualidad e hipertextualidad. La intertextualidad es una relación de copresencia entre dos o más textos, la presencia efectiva de un texto en otro. Esta presencia puede ser a través de citas, plagio o alusión (p. 10). La paratextualidad es la relación que el texto mantiene con el título, subtítulos, intertítulos, prefacios, epílogos, advertencias, prólogos, notas al margen, notas al pie de página, epígrafes, ilustraciones, etcétera (p.11). La metatextualidad es la relación que une un texto a otro que habla de él sin citarlo o sin nombrarlo (p.13). La architextualidad es una relación completamente muda que, como máximo, articula una mención paratextual, como para clasificar (p. 13). Y la hipertextualidad es la relación que une a un texto llamado hipotexto con un texto B llamado hipertexto. A se injerta en B sin que sea comentario. B es un texto derivado de un texto preexistente. B no puede existir sin A. B es la transformación de A. "Evoca más o menos explícitamente, sin necesariamente hablar de él y citarlo" (p. 14).

Genette (1989) también sostiene que los tipos de transtextualidad no son excluyentes unos de otros. "No se deben considerar los cinco tipos de transtextualidad como clases estancas, sin comunicación ni entrelazamientos recíprocos. Por el contrario, sus relaciones son numerosas y a menudo decisivas" ( $p$. 17).

De todos los tipos de transtextualidad, la intertextualidad es la que ha sido más problemática y más estudiada. Puesto que nuestro interés está en la intertextualidad, abundaremos en su definición y caracterización. 
La intertextualidad es la relación de un texto con otro u otros, la producción de un texto desde otro u otros precedentes. Supone la preexistencia de otros textos, la lectura interactiva, lineal y tabular a la vez (Martínez, 2001, p. 37).

Todo texto tiene una relación con otros. Es difícil encontrar un texto totalmente original y aislado. "Todo texto es un montaje de textos citados, mencionados, evocados, que se colocan en una suerte de 'profundidad' textual [...] No hay enunciación estrictamente individual, sino más bien re-enunciaciones individuales de un sustrato textual y cultural colectivo" (Fontanille, 2012, p. 155).

Por lo tanto, el uso o la interpretación del texto obliga a establecer relaciones intertextuales.

Todo texto es hijo de una cultura, porque depende de materiales afines a esa cultura y ella ocupa un lugar también en el texto. Por lo mismo, la producción textual, de una u otra manera, manifiesta lo ya dicho y tratado previamente por otros autores en el interior de ámbito cultural. Un discurso habla siempre de sí mismo; pero también, de los demás discursos, de los cuales depende (Zecchetto, 2010, p. 330).

La intertextualidad la establecen los autores, los productores y los realizadores, pero también los lectores, los consumidores y los espectadores. Se refiere a la:

Relación de dependencia que se establece entre, por un lado, los procesos de producción y de recepción de un texto determinado $y$, por otro, el conocimiento que tengan los participantes en la interacción comunicativa de otros textos anteriores relacionados con él (Martínez, 2001, p. 38).

Fontanille (2012) sugiere diferenciar entre la intertextualidad como relación entre textos y la intertextualidad como relación entre discursos o sistemas de valores. La intertextualidad puede tratarse como una relación entre discursos o textos, como dialogismo o intertextualidad estrictamente.

La polifonía concierne al discurso, a su orientación, a sus sistemas de valores, a sus actos de lenguaje, mientras que la intertextualidad tiene que ver con el texto, con su dispositivo formal, con las imbricaciones entre segmentos textuales y con la superposición de los planos de enunciación, así como con la morfología lingüística de su incorporación y de su transposición por el texto que los acoge (Fontanille, 2012, p. 156).

En esta investigación, se entiende la intertextualidad como un hecho que corresponde al texto y al discurso. Es decir, como fragmentos de un texto que encontramos en otro y como diferentes voces, variedades o registros lingüísticos que encontramos en un mismo texto. Sin embargo, enfatizamos en la relación de textos, ya que es más operativa para esta investigación. 
En ese sentido, una manera de operacionalizar el concepto de intertextualidad es el siguiente: T=IT+ET. Donde $\mathrm{T}=$ texto, $\mathrm{IT}=$ intertexto y $\mathrm{ET}=$ exotexto. Un texto es igual a la suma del intertexto más el exotexto. Se entiende que el intertexto es el fragmento tomado de un texto anterior. Así, un Texto A (texto anterior) puede influir en el Texto B (texto nuevo). El Texto B es igual a la suma del intertexto más el exotexto. $Y$ el Texto A contiene el intertexto del Texto B que en el Texto A funciona como subtexto (Martínez, 2001, p.77).

\section{La cooperación y la competencia}

Los textos, verbales o audiovisuales, requieren una actualización por parte de los que lo leen o lo consumen. "Un texto, tal como aparece en su superficie (o manifestación) lingüística, representa una cadena de artificios que el destinatario debe actualizar" (Eco, 2013a p. 69). Por lo tanto, "en la medida en que debe ser actualizado, un texto está incompleto" (Eco, 2013, p.69), ya se trate de un texto escrito, ya se trate de un filme o una serie. Para que un texto sea completado o actualizado, es necesario un buen performance del lector-usuario. Se requiere capacidades. En suma, se necesita competencia. "Todo mensaje postula una competencia gramatical por parte del destinatario" (Eco, 2013a, p. 69).

Esta cooperación del destinatario es necesaria para que la interpretación o el uso del texto esté completo. "Un texto [...] requiere ciertos movimientos cooperativos, activos y conscientes, por parte del lector" (Eco, 2013a, p. 70). Por lo tanto, diremos que es necesario un lector-usuario modelo, que reúna las competencias tanto para la interpretación como para el uso, que tenga la capacidad de cooperar.

Un texto postula a su destinatario como condición indispensable no solo de su propia capacidad comunicativa concreta, sino también de la propia potencialidad significativa. En otras palabras, un texto se emite para que alguien lo actualice; incluso cuando no se espera (o no se desea) que ese alguien exista concreta y empíricamente (Eco, 2013a, p.72).

Sin embargo, es importante destacar que la competencia de los productores y de los destinatarios no tiene que ser igual necesariamente. "La competencia del destinatario no coincide necesariamente con la del emisor" (Eco, 2013a, p. 73).

Para referirse a los lectores modelos de las obras literarias, Eco (2012) clasifica en dos tipos: el lector semántico y el lector crítico o estético o semiótico (p. 231). El lector semántico es el que está interesado en saber cómo acaba la historia y hace una lectura de primer nivel. El lector crítico, estético o semiótico quiere descubrir los procedimientos del autor (p. 234). 
La interpretación semántica o semiósica es el resultado del proceso por el cual el destinatario, ante la manifestación lineal del texto, la llena de significado. La interpretación crítica o semiótica es, en cambio, aquella por la que se intenta explicar por qué razones estructurales el texto puede producir esas (u otras, alternativas) interpretaciones semánticas (Eco, 1992, p. 36).

Cada tipo de lector requiere desplegar cierto esfuerzo. Así, se puede hablar de dos niveles de interpretación.

El lector de primer nivel quiere saber qué sucede, el de segundo nivel cómo se relata lo que sucede. Para saber cómo acaba la historia basta, normalmente, leer una sola vez. Para convertirse en lector de segundo nivel es preciso leer muchas veces, y algunas historias hay que leerlas un sinfín de veces. No existen lectores exclusivamente de segundo nivel; es más, para llegar a serlo hay que haber sido buen lector de primer nivel [...] Lo seguro es que se puede ser lector de primer nivel sin acceder nunca al segundo (Eco, 2012, p.234).

Tanto el lector-espectador semántico como el lector-espectador semiótico requieren ciertas competencias para una cooperación óptima. Una de las competencias que se requiere es la intertextual. La intertextualidad puede verse desde el creador de la obra que ha dejado que otras obras influyan en la suya, pero también puede verse desde los destinatarios que tiene la capacidad de relacionar el texto que leen con otros.

La competencia intertextual puede ser parte de lo que se ha llamado competencia mediática (Ferrés y Piscitelli (2012). Esta última se define como la combinación de conocimientos, destrezas y actitudes que se consideran necesarios para afrontar la nueva ecología de medios digitales en la que se encuentran el destinatario y el destinador de mensajes. Esta competencia tiene seis dimensiones: lenguajes, tecnología, procesos de interacción, procesos de producción y difusión, ideología y valores, y estética. Dos de los 55 indicadores que se establecen son: capacidad de establecer relaciones entre textos -intertextualidad-, códigos y medios, elaborando conocimientos abiertos, sistematizados e interrelacionados. Y la capacidad de relacionar las producciones mediáticas con otras manifestaciones artísticas, detectando influencias mutuas.

La competencia mediática y la competencia intertextual son necesarias tanto para el uso como para la interpretación de textos o de productos audiovisuales en la actualidad. Por lo tanto, su desarrollo es importante. 


\section{Uso e interpretación}

Umberto Eco (1992, 2013a) propone distinguir entre uso e interpretación de textos. Usar se relaciona con la intención que tiene el lector respecto del texto. Puede usarlo para gozar, para informarse, para educarse o para interpretar otra cosa. Siguiendo la Teoría de usos y gratificaciones, se puede afirmar que los textos pueden ser usados para satisfacer necesidades como: diversión, escape de las presiones de la rutina, escape del peso de los problemas, escape emocional; relaciones personales, compañía, utilidad social, para tener temas de conversación y para conocer experiencias; identidad personal, referencia personal, comparaciones con personajes; exploración de la realidad, comprenderla; refuerzo de valores; vigilancia, necesidad de información. Un texto puede usarse para realizar interpretaciones más allá del texto. Por ejemplo, usar las telenovelas para explicar la violencia contra la mujer o para aprender la historia de un país.

La interpretación, en cambio, es la identificación de significados y sentidos del texto. Se relaciona con la identificación de la intencionalidad del texto, que es importante diferenciarla de la intención del autor concreto. Mientras la intención del autor es un fenómeno psicológico y difícil de saberlo, la intencionalidad del texto se desprende del mismo texto. La interpretación, como lo mencionamos anteriormente, puede ser de dos niveles.

El uso y la interpretación de los textos conllevan necesariamente a establecer relaciones de transtextualidad, especialmente de intertextualidad.

El establecimiento de relaciones intertextuales puede ser muy amplio y, tal vez infinito. Por ejemplo, una serie televisiva puede tener relaciones intertextuales con otras series o con otros géneros audiovisuales. Pero también puede tener relaciones intertextuales con obras literarias, históricas o científicas. Por lo tanto, toda lectura intertextual debe delimitarse.

\section{La historia}

El problema planteado en esta investigación implica relacionar una serie televisiva y un libro sobre un personaje muy importante para la historia del Perú y América del Sur. Por ello, se recurre la teoría de la historia. Si bien son claras las diferencias entre historia y literatura o entre historia y ficción televisiva, también es cierto que tienen varias características comunes: son textos basados en otros textos, expresan un punto de vista y son maneras de contar el pasado.

Se entiende que la historiografía es un discurso elaborado sobre otros discursos, un texto elaborado sobre otros textos. Es decir, el historiador no observa la realidad ni los hechos históricos, sino los lee en los textos que dan cuenta de ellos. 
Hoy se da por sentado que la historia, cualquiera sea su designio particular, es un discurso que prescribe los hechos atribuidos al tiempo pasado de una o varias comunidades [..] en lo esencial el texto histórico solo tiene como asidero los distintos discursos escritos ora en documentos ora en los textos de otros historiadores; en efecto, para el historiador no hay "realidad" que no esté escrita" (Ballón, 2014, p. 15).

La historiografía organiza los hechos del pasado. No muestra la realidad, sino un punto de vista acerca de ella. El historiador hace una selección de hechos contados en los textos. La historiografía, entonces, es una construcción de la realidad. "No hay neutralidad, el historiador escribe, se compromete" (Ballón, 2014, p.35).

La historiografía no es el único discurso sobre la realidad pasada. Existen otros discursos que también dan cuenta del pasado: el periodismo, las novelas, el folclore, entre otros.

La historia no tiene el monopolio del discurso sobre el pasado: el folclore, las novelas "realistas", el periodismo, los museos, los documentales, la fotografía, la arqueología, el psicoanálisis, los procesos judiciales, etc., producen igualmente relatos sobre el pasado" (Ballón, 2014, p. 24).

A estas formas de contar el pasado hay que sumarles los discursos audiovisuales realistas y ficticios, como las telenovelas, las películas, las series y los documentales. Pero muchos de estos discursos sobre el pasado, no tienen necesariamente la finalidad de dar cuenta directamente de los hechos históricos pretéritos, sino expresarlos e interpretarlos figuradamente.

El fin de la novela histórica no es representar hechos más o menos verdaderos ni dar lecciones de historia sino hacer reflexionar sobre las trazas y rastros semisimbólicos de las actividades humanas (Ballón, 2014, p. 139).

Muchas veces las novelas, las telenovelas, las series, más que grandes hechos históricos, muestran hechos personales, individuales, pero que forman parte de macrohechos. "Gengenbre sostiene que la ficción dice la complejidad de lo social y las contradicciones de la historicidad humana antes que reflejarlas" (Ballón, 2014, p. 140).

Lo que hace un historiador no es muy diferente a lo que hace un novelista o un guionista de televisión. Puesto que no tiene acceso al hecho real pasado, sino a textos que dan cuenta de él, y puesto que solo conoce los hechos aislados, el historiador busca dar cuenta de un macrohecho, de una sociedad en un tiempo determinado. Por lo tanto, esa imagen global de los hechos, de las sociedades, de las épocas, solo puede ser imaginada por el historiador. "El historiador busca siempre la "coherencia, integridad, plenitud y conclusión de una imagen de la vida que es, y solamente puede ser, imaginaria" (Ballón, 2014, p.143). 
Para los fines de esta investigación, se asume la teoría formal de la obra histórica propuesta por Hayden White en Metahistoria. La imaginación histórica en la Europa del siglo XIX. Este libro constituye un hito de lo que se ha dado a llamar el giro lingüístico en las concepciones de la historia.

White define una obra histórica como "una estructura verbal en forma de discurso de prosa narrativa que dice ser un modelo, o imagen, de estructuras y procesos con el fin de explicar lo que fueron representándolos" (White, 1992, p. 14). Según él, una obra histórica combina "cierta cantidad de datos, conceptos teóricos para explicar esos datos y una estructura narrativa para presentarlos como la representación de conjuntos de acontecimientos que supuestamente ocurrieron en tiempos pasados" (White, 1992, p. 9).

En una obra histórica, se pueden identificar las siguientes dimensiones: epistemológicas, estéticas y morales.

Distingo entre tres tipos de estrategias que los historiadores pueden emplear para obtener distintos tipos de "efecto explicatorio". He llamado a esas diferentes estrategias explicación por argumentación formal, explicación por la trama y explicación por implicación ideológica. Dentro de cada una de ésas diferentes estrategias identifico cuatro modos posibles de articulación por los cuales el historiador puede conseguir un efecto explicatorio de un tipo específico. Para la argumentación tenemos los modos de formismo, organicismo, mecanicismo y contextualismo; para la trama tenemos los arquetipos de la novela, la comedia, la tragedia y la sátira; y para la implicación ideológica tenemos las tácticas del anarquismo, el conservadurismo, el radicalismo y el liberalismo (White, 1992, p. 9).

La combinación de estas tres estrategias produce lo que White llama el "estilo historiográfico" de un historiador. "Un estilo historiográfico representa una combinación particular de modos de tramar, de argumentación y de implicación ideológica" (White, 1992, p. 38). Pero como esa combinación no puede ser de todo tipo, White encuentra afinidades entre los que se muestra en la tabla siguiente:

\section{Tabla 1}

Estilos historiográficos

\begin{tabular}{lll}
\hline Modo de tramar & Modo de argumentar & Modo de implicación ideológica \\
\hline Romántico & Formista & Anarquista \\
\hline Trágico & Mecanicista & Radical \\
\hline Cómico & Organicista & Conservador \\
\hline Satírico & Contextualista & Liberal \\
\hline
\end{tabular}

Nota. White, 1992, p. 39 
Así, si se quisiera analizar la obra de un historiador, se tendría que responder: a) ¿Su argumentación se caracteriza por ser formista, organicista, mecanicista o contextualista? ¿Cuáles son esos argumentos? b) ¿La trama es de novela, comedia, tragedia o sátira? ¿Cómo se presenta? c) ¿Su implicación ideológica es anarquista, conservadurista, radicalista o liberalista? ¿Cuáles son sus postulados?

Según White, en una obra histórica hay un nivel profundo en la que se encuentra la conciencia histórica del historiador. En esa conciencia histórica, el historiador "escoge estrategias conceptuales por medio de las cuales explica o representa sus datos" (White, 1992, p. 10). Esta conciencia histórica prefigura el campo histórico a través de la metáfora, la metonimia, la sinécdoque y la ironía, que son formas del pensamiento histórico.

Estas características de la obra histórica han llevado a equiparar una obra histórica a una obra literaria. La historia no es una ciencia sino un arte. Por lo tanto, según Hayden White, cuando se analiza una obra histórica se debe preguntar ¿cuáles son los elementos artísticos de la historiografía realista? Por el contrario, cuando se analiza una obra artística, se debe preguntar ¿cuáles son los componentes históricos del arte realista?

Siguiendo a White, preguntamos: ¿cuáles son los componentes históricos de la serie o la telenovela histórica? Y dado que no se puede tener acceso a la realidad sino solo a textos, esta pregunta solo se puede responder a través del reconocimiento de la intertextualidad.

\section{El género, el formato}

Se diferencia entre serie y serial televisivos. La primera cuenta una historia completa en cada episodio, mientras que el segundo lo hace en varios episodios. Sin embargo, esta distinción no ha prosperado, ya que se les llama serie a ambas formas de contar. También, se ha diferenciado entre serie y telenovela. La serie es un modelo narrativo estadounidense y la telenovela es un modelo narrativo latinoamericano (Gómez, 2019). Sin embargo, también esta distinción no está clara, ya que se llaman series a las telenovelas y telenovelas a las series, sobre todo en las plataformas de streaming como Netflix. Así, para caracterizar mejor a nuestro objeto de estudio, recurrimos a los conceptos de telenovela.

La telenovela tiene sus raíces en el melodrama del siglo XVIII y los folletines del siglo XIX, ambos movimientos europeos (Barbero, 1988). La telenovela, tal como la conocemos hoy, nació en Cuba en 1952. Es un "formato televisivo para contar historias en tono de melodrama y es un producto cultural que responde a las necesidades de reconocimiento de las masas desposeídas de mayores relatos" (Rincón, 
2008). Se caracteriza por contar sobre los amores contrariados desde la perspectiva femenina y el ascenso social vía el amor o la justicia, siempre con final feliz (Rincón, 2008).

Las telenovelas también han contado temas históricos. Así, es posible hablar de telenovelas históricas. María de los Ángeles Rodríguez Cadena (2004) la define como:

Melodrama televisivo que representa un periodo específico de la historia colectiva y a sus héroes principales, y lo complementa con la historia de personajes no históricos que interconectan subtramas de pasión, amor, celos, traición e intriga, historias tradicionales de telenovela. La autora plantea que las telenovelas históricas mezclan personajes de la historia con gente común y hechos históricos con escenas de lo cotidiano, por lo que este tipo de melodramas televisivos enfatizan la integración del ciudadano ordinario como un acompañante leal de las figuras históricas (Charlois y Orozco, 2010, p.26).

Existen dos formas de presentar la historia en las producciones audiovisuales. El modelo 1 implica el recurso de historias paralelas (historia nacional-historia familiar) que vincula al televidente con la trama nacional. Entrelazar historias familiares con la historia nacional tiene el efecto de acercar al televidente al recrear el drama humano propio de los acontecimientos (Charlois y Orozco, 2010, p.27-28). El modelo 2 implica que el personaje histórico central funciona más como un articulador de lo melodramático, disminuyendo en cierto sentido la dependencia de historias ficticias paralelas (Charlois y Orozco, 2010, p.27).

Hoy, en muchos casos, las telenovelas y las series televisivas parecen tener más características comunes que diferentes: Ambas cuentan historias por entregas durante un tiempo prolongado y combinan melodrama y acción. Así, en esta investigación se usarán indistintamente los términos "serie" y "telenovela" para referirse al objeto de estudio.

\section{Método}

Enfoque y diseño. Esta investigación tuvo un enfoque cualitativo y un diseño interpretativo. Se interpretaron textos para identificar en ellos las relaciones intertextuales.

Objeto de estudio. Bolívar, una lucha admirable es una serie televisiva o telenovela producida por la empresa colombiana Caracol Televisión. Se estrenó en 2019. Y se exhibe en Netflix. 


\section{Trayectoria metodológica}

a) Primer visionado de la serie: Se seleccionó la versión completa de la serie Bolívar, una lucha admirable que se presenta en Netflix. Esta tiene una temporada y 60 episodios. Cada episodio dura 45 minutos en promedio, lo que equivale a 48 horas o 2 días aproximadamente.

Este primer visionado permitió tener un conocimiento inicial de la historia contada: los temas, los personajes y las situaciones que fueron tomados de otros textos. Se encontró que la serie tiene relación intertextual con textos de historia, política y cultura.

b) Selección de la intertextualidad: La serie seleccionada para este estudio tiene como tema la vida de Simón Bolívar. Por eso, se eligió conocer su relación intertextual con los textos de biógrafos peruanos.

c) Selección del Texto A: En una entrevista, Juana Uribe, la creadora de Bolívar, una lucha admirable, contó que la serie fue escrita por ella, pero tuvo un equipo de asesores conformado por Ricardo Aponte, María Clara Torres, Leonor Sardi, Laura Rojas y dos historiadores. Revisaron las biografías escritas por Indalecio Liévano (1956), Gerard Masur (1960), John Lynch (2006) y Marie Arana (2013), las Cartas de Bolívar, entre otros textos. No se menciona ni se sugiere Bolívar, libertador y enemigo número 1 del Perú, obra de Herbert Morote Rebolledo, publicada en Lima en 2007. Sin embargo, Morote hace referencia a todos los autores mencionados por Juana Uribe, salvo a Marie Arana que publicó después. Así, se eligió como texto A la biografía de Bolívar escrita por Morote.

\section{Tabla 2}

Texto $A$ y Texto $B$ seleccionados para la investigación

Texto A Texto B

(1) Bolívar, libertador y enemigo

(1) La serie Bolívar, una lucha número 1 del Perú admirable

d) Identificación de los subtextos: A través de la lectura y el fichaje del Texto A, se identificaron los posibles subtextos.

e) Segundo visionado de la serie e identificación de los intertextos: Se realizó un segundo visionado de la serie. Esta vez, para reconocer en ella los intertextos. Para el registro, se utilizó una tabla de dos columnas: una para los subtextos y otra para los intertextos. 


\section{Resultados}

Bolívar, una lucha admirable es una serie o una telenovela histórica. Corresponde al modelo 2 de telenovelas históricas. El personaje principal es Simón Bolívar y en torno a él aparecen muchos personajes históricos, pero también ficticios. El hilo conductor del relato es la vida de Simón José Antonio de la Santísima Trinidad Bolívar Palacios Ponte y Blanco (1783-1830). Se pone énfasis en sus relaciones amorosas y en el papel de las mujeres en la historia. Aparecen la madre, la hermana, la primera esposa, la segunda esposa y, finalmente, Manuelita Sáenz, cumpliendo no solo el papel de acompañante de Bolívar, sino orientando el rumbo de la historia. No solo aparecen las mujeres de Bolívar, sino también la amante de Santander, Nicolasa, y la de San Martín, Rosa Campuzano. Para el encuentro en Guayaquil, la información que brinda Manuelita Sáenz a Bolívar es más importante que la estrategia diseñada por sus generales Sucre y Córdova y de lado de San Martín, los consejos de Rosa Campuzano.

Si bien, por el formato, Bolívar es presentado como el personaje épico y el bueno de la historia, la telenovela tiene conexiones intertextuales con la biografía escrita por Herbert Morote. Ciertamente, los títulos de ambos textos (Bolívar, una lucha admirable y Bolívar, libertador y enemigo número 1 del Perú) ya dicen que son dos visiones contrarias de la vida del Libertador. Sin embargo, pueden establecerse relaciones intertextuales entre ellos.

Se encontraron las siguientes relaciones intertextuales: citas y alusiones. Existen semejanzas en la presentación global de Simón Bolívar en relación con el Perú; la Batalla de Pichincha; la entrada de Bolívar a las ciudades; las situaciones previas y el encuentro en Guayaquil entre Simón Bolívar y San Martín; los acontecimientos previos y la llegada de Bolívar al Perú; las batallas de Junín y Ayacucho; la Constitución vitalicia; y los últimos días de Bolívar en Perú y su salida. A continuación, se presentan los subtextos y los intertextos correspondientes: 
Tabla 3

\section{Presentación global de Simón Bolívar}

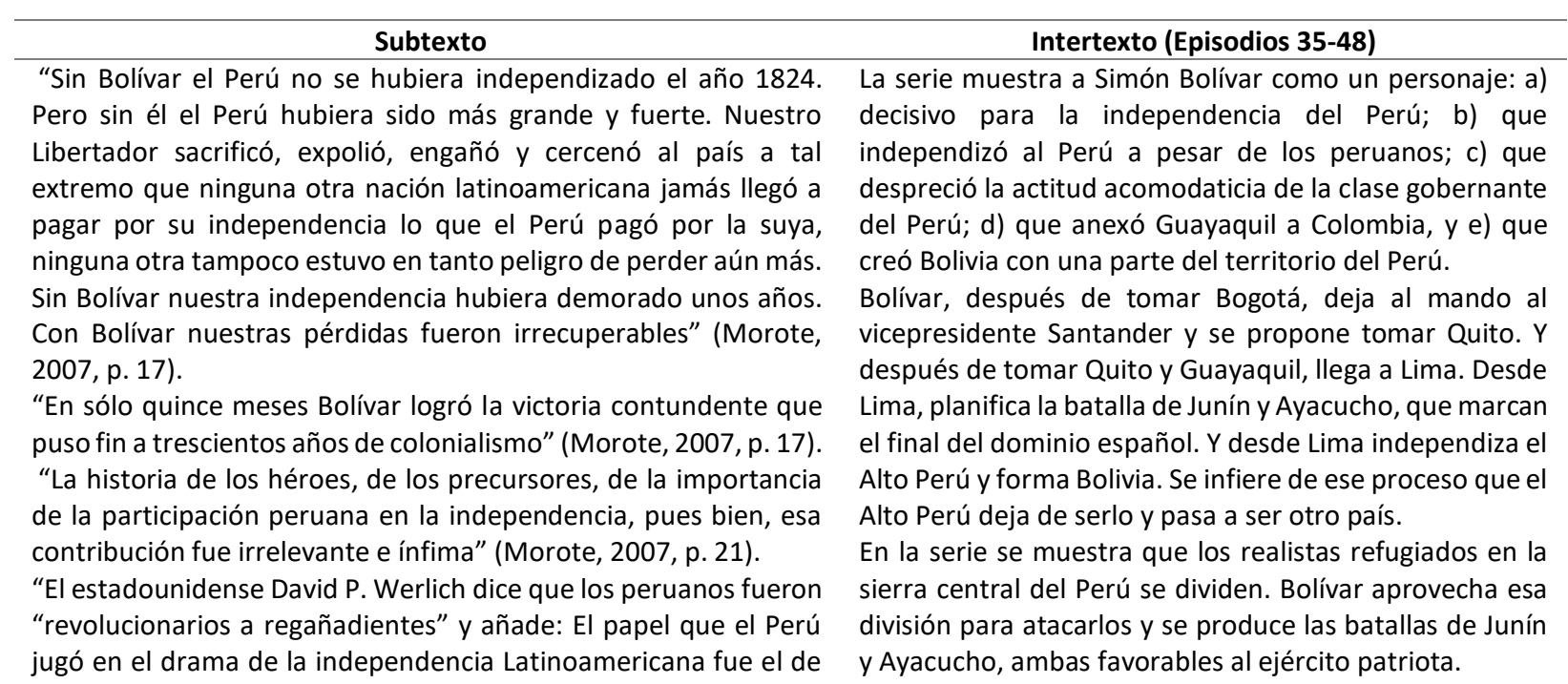
un espectador interesado en el Acto Final. Las guerras por la independencia en todas las colonias españolas fueron guerras civiles entre los criollos independentistas contra criollos pro realistas. $Y$ en ninguna parte el sentimiento pro realista fue más fuerte que en el Perú. A pesar de las desventajas del sistema colonial, en Lima se concentraba una desproporcionada fuente de beneficios que seguía existiendo del antiguo régimen. Había dentro de los peruanos más de 100 nobles y muchos burócratas imperiales. Aún más, la rebelión de Tupac Amaru II asustó a la clase alta criolla y desalentó cualquier discrepancia dentro de las élites que podrían haber llevado a las clases oprimidas a rebelarse nuevamente" (Morote, 2007, p. 22).

\section{Tabla 4}

\section{Batalla de Pichincha}

Subtexto

24 de mayo de 1822. "El Perú, en un acto histórico poco o insuficientemente realzado por los historiadores y gobiernos peruanos, envió desde Trujillo una división de 1,622 hombres al mando de Santa Cruz, en auxilio de Sucre. Esto sí fue un acto de fraternidad cercano a la imprudencia, ya que en Lima San Martín a duras penas se defendía de los asedios de las fuerzas del virrey" (Morote, 2009, p.23).

\section{Intertexto (Episodio 36)}

La serie no muestra la batalla de Pichincha en una escena. Se presenta a través de las conversaciones de los involucrados.

Bolívar iba de Bogotá a Quito, para ayudar a Sucre. Sin embargo, se detuvo en enfrentamientos con los realistas en Pasto y no llegó a tiempo.

El coronel O'Leary narra: “De la mano decidida del general Sucre y con los soldados que venían de Colombia, Argentina y Perú, el ejército patriota venció en Pichincha al ejército del Rey".

Se realiza una fiesta para celebrar el triunfo de los patriotas y la toma de Quito, pero Bolívar no celebra. Está en la fiesta, pero no está contento. Le dice a Sucre: "Esta es tu fiesta y Pichincha es tu victoria".

Más, adelante, Bolívar reconoce que el Perú le envió 1600 soldados. 


\section{Tabla 5}

\section{Entrada de Bolívar a las ciudades}

\begin{tabular}{l} 
Subtexto \\
\hline "La entrada de Bolívar a Guayaquil -igual a sus entradas anteriores \\
en otras ciudades independizadas, así como sus futuras entradas a \\
Lima o La Paz - fue cuidadosamente planeada. Se anunció con la \\
debida anticipación para que el pueblo y sus agentes preparasen \\
arcos triunfales, flores, bandas de música, bailes, etcétera. Un \\
relacionista público del siglo XXI tendría mucho que aprender de él" \\
(Morote, 2007, p.29) \\
"Cuando llegó a Lima y el pueblo enfervorizado salió a la calle para \\
verlo llegar acompañado del Presidente Torre Tagle y sus ministros, \\
que habían ido a caballo hasta el Callao para rendirle cortesanas \\
pleitesías. Toda la ciudad estaba engalanada con flores y, al igual, que \\
a su entrada a Guayaquil, hubo salva de cañones, clamoreo de \\
campanas, bailes populares, jolgorio general. La entrada de Bolívar \\
en Lima tuvo el mismo boato que la de los virreyes cuando venían a \\
tomar posesión de su virreinato" (Morote, 2007, p. 45-46).
\end{tabular}

\section{Intertexto (Episodio 36)}

En la serie se muestra que Bolívar siempre envía un grupo de avanzada a la ciudad para que prepare su arribo. Cuando llega Bolívar la gente lo espera e ingresa entre aplausos. Esto pasa en Bogotá y en Quito. Sin embargo, cuando llega al Perú, Bolívar es recibido solamente por el presidente Torre Tagle y se asienta en las afueras de la ciudad, a 7 kilómetros.

\section{Tabla 6}

Situaciones previas y el encuentro en Guayaquil entre Simón Bolívar y San Martín

\section{Subtexto}

"A fin de ponerse de acuerdo sobre el fin del dominio español en América, San Martín y Bolívar acordaron tener una conferencia en Guayaquil. Allí llegó nuestro Protector sin sospechar que Bolívar le había tendido la trampa de apoderarse días antes de Guayaquil. Por eso cuando su goleta Macedonia ancló frente al puerto y recibió abordo la visita de los edecanes de Bolívar, tuvo que contener mal su enfado al oír que lo invitaban a desembarcar "en territorio colombiano". El mensaje no podía ser más claro: Bolívar no estaba dispuesto a negociar el puerto ni la gloria" (Morote, 2007, p.30).

"En ningún momento de las conversaciones San Martín protestó por la pérdida de Guayaquil. Sobre este espinoso asunto se limitó a salvar la cara y pidió que se celebrasen comicios libres para que el pueblo decidiese su futuro, solicitud que Bolívar concedió, confiado que en el peor de los casos la presencia de sus tropas y sus agentes conseguirín la adhesión a Colombia" (Morote, 2007, p. 30).

"Lo que a San Martín le preocupaba principalmente era mantener el orden de las cosas cuando desapareciese el virreinato. Quizá puede ser discutible su idea de una monarquía constitucional, pero, como Hobbes, lo que más temía era el caos. Un referéndum popular daría respaldo jurídico a esta forma de gobierno. Bolívar, en cambio, decía ser partidario de no consultar nada a la gente pues sentía "el respaldo de los pueblos tras de sus decisiones" (Morote, 2007, p. 31).

"La discusión del segundo día de la conferencia la cuenta Liévano de la siguiente manera: (...) El general argentino pensó en la posibilidad de celebrar con Bolívar - de quien tenía un concepto mediocre- un tratado de alianza que le fuera prestada como lo había hecho Chile abnegadamente, entregándole reclutas y armamentos para engrosar los cuerpos argentinos que actuaban con personalidad propia en el Perú. De esta manera lograba adelantar con recursos de otros pueblos una empresa continental que aparecía como argentina (...) En la actitud de San Martín no había, pues, el altruismo y desprendimiento
Bolívar está en Quito y recibe una carta de San Martín. Se van a reunir en Guayaquil. Bolívar le pide a Sucre y Córdova para que diseñen una estrategia para esa reunión.

Manuelita Sáenz le dice a Bolívar que la clave está en entender cuál es el estado de San Martín. Le informa que sufre de reumatismo y está abatido.

Bolívar afirma que esa información es valiosísima. Y añade: "El general San Martín y yo tenemos una gran diferencia de fondo. Él cree que Guayaquil debe Pertenecer a Perú y yo creo que debe pertenecer a Colombia".

Manuelita: "Error gravísimo, porque históricamente Guayaquil y Quito siempre han pertenecido a Colombia, nunca a Lima".

Bolívar: "Me alegra que también usted lo piense". Manuelita: "Yo creo que el general San Martín quiere hablar del Perú. Él quiere establecer una monarquía".

Bolívar: "No he escuchado una estupidez más grande. iUn reino en América! Nos pidió ayuda. Pensé en devolverle la ayuda que nos dio, 1600 hombres".

Manuelita: "Si el general San Martín quiere sacar a todos los realistas que están alrededor de Lima, que no son pocos, con 1600 hombres no lo va lograr. Él quiere todo su ejército. Está muy debilitado".

Bolívar: "No necesita mi ejército, me necesita a mí". Manuelita: "Pero nunca lo va a aceptar, porque el general San Martín, puede estar débil, pero tiene 
que le atribuyen sus panegiristas, sino astucia y habilidad politica. (...) Sobre estas bases, sin embargo, el entendimiento resultaba imposible. Con discreción, pero con firmeza, así se lo dejó ver Bolivar manifestándole contrario a los intereses de su pueblo el procedimiento de "poner las tropas de un estado al servicio del otro". Fue entonces posiblemente cuando San Martín insinuó, por reacción muy natural y contradiciéndose con afirmaciones anteriores suyas dijo "que el enemigo (España) es menos fuerte que él y que sus jefes, aunque audaces y emprendedores, no son muy terribles»). (...) [Bolivar] sabía al general argentino falto de fuerzas necesarias para decidir la campaña del Perú y conocía que en Lima había ocurrido en esos días un movimiento de insurrección contra el gobierno del Protector, movimiento que había logrado bajo la dirección de Riva-Agüero notables éxitos iniciales.

(...) Por lo tanto, sin ninguna clase de equívocos, Bolívar manifestó a San Martín cómo a la satisfacción de conocerle personalmente, agregaba ahora la de enterarse, por su boca, que la guerra en el Perú no presentaba problemas insuperables para los ejércitos argentinos y que con gusto le proporcionaría la división acantonada en Guayaquil, cuyos efectivos ascendían a 1,800 hombres, los cuales, dadas las afirmaciones optimistas del Protector, eran suficientes (...) San Martín experimentó la dureza del golpe, pero nada pudo hacer para evitarlo: 1,800 hombres, como él y Bolívar sabían, poco aportaban a la solución del problema militar del Perú. (...) Al atardecer, San Martín se anticipó a poner fin a su última entrevista, en la cual habían naufragado todas sus esperanzas, y anunció a Bolívar su propósito de partir inmediatamente rumbo al Perú. El Libertador le informó que se había organizado un baile en su honor para aquella noche y le solicitó aplazar su partida (...). Esa noche pudo la sociedad de Guayaquil contemplar, en la suntuosa sala de la Casa de Gobierno, en medio del brillo de los uniformes, las de las damas y la animación general (...) San Martín frío, reservado y cortés, recibiendo en uno de los ángulos del salón los saludos y los homenajes; y a Bolivar, más alegre que nunca, danzando con el entusiasmo que por el baile siempre se caracterizó. Hacia la madrugada, San Martín hizo a comunicar a Bolívar su deseo de retirarse y, acompañado por él, salieron discretamente y se dirigieron al muelle donde estaba todo preparado para la partida (...) y San Martín subió silenciosamente a la lancha que debía conducirlo al Macedonia. Al amanecer del día 28, el barco levaba anclas rumbo al Perú (Morote, 2007, p. 33).

"Lograda la independencia de Ecuador y previsto el retiro de San Martín del gobierno, Bolívar tenía las puertas abiertas para ir al Perú No importaba si los peruanos lo quisieran o no, el Libertador sabía que no podían lograr una pronta independencia sin su apoyo. A partir de ese momento se dedicó con ahínco a formar un ejército para su campaña y a socavar los gobiernos peruanos que sucedieron a San Martín" (Morote, 2007, p. 33). una soberbia enorme. Ustedes dos no caben en la misma habitación".

Bolívar: "Voy a llegar antes que el general San Martín y mostrarle quién es el ejército patriota".

La serie muestra que Manuelita tenía mejor estrategia que sus generales. Tenía información de primera mano sobre San Martín, aquella que le proporcionó Rosita Campuzano, amante de San Martín.

\section{Primer encuentro de Bolívar y San Martín}

Afinando sus estrategias, ambos evalúan sus fortalezas y debilidades.

O'Leary le informa a Bolívar que San Martín tiene 44 años

San Martín llega con Rosita Campuzano. Ella le informa sobre Bolívar. Pero San Martín cree tener más mérito. Bolívar tiene 38 años.

Bolívar: "Yo tengo claro que Guayaquil pertenece a Quito".

Antes de empezar la reunión, Bolívar envía una nota a Manuelita Sáenz. Bolívar y San Martín se reúnen a solas, mientras el general Sucre, el coronel Córdova y Rosita Campuzano los esperan.

San Martín le propone formar un ejército conjunto para liberar lo que queda de América y que sea dirigido por Bolívar.

Bolívar: “¿Y Usted?"

San Martín: "Estaría bajo su mando".

Bolívar: "Eso no lo permitiría jamás, por antigüedad".

San Martín: "Y sobre Guayaquil, hay que hacer elecciones para ver si la gente quiere pertenecer al Perú, a Colombia o quieren ser independiente".

Bolívar: "Siempre ha pertenecido a Colombia".

San Martín: “¿No le gusta la democracia?”

Bolívar: "No me gusta preguntarle a la gente lo que ya es sabido".

San Martín: "Piénselo".

Bolívar: "Suponiendo que acepto su propuesta, ¿qué clase de gobierno propondría?"

San Martín: "Una monarquía".

Bolívar: “¿Perdón?”

San Martín: "Usted no conoce la naturaleza de la sociedad de Lima. Ellos no saben vivir sin castas. Necesitan saber quién está arriba y quién está abajo".

Bolívar: "No liberamos a América para poner un rey en el Perú".

San Martín: "No sería un rey, sino un príncipe independiente que venga de Europa. Le estoy pidiendo que me crea, general. Otro tipo de régimen no funcionaría en el Perú".

Bolívar: "Pero si se volvieron patriotas con una facilidad impresionante".

San Martín: "Y se volverán realistas con la misma facilidad".

San Martín está cansado de la discusión.

Bolívar: "Ambas propuestas merecen meditarse. Veámonos en unos días". 
San Martín después del primer encuentro San Martín a Rosita Campuzano: "Yo no tengo nada que pensar. Yo sé exactamente lo que se necesita. El que propuso todo fui yo".

Segundo encuentro de Bolívar y San Martín, en una iglesia de Guayaquil

Aquí el diálogo:

Bolívar: "Supongamos que le presto mi ejército y ¿qué viene después?"

San Martín: "Una monarquía”.

Bolívar: "Sería ridículo".

San Martín: "Sería solo en el Perú. Ellos no están preparados para una democracia".

Bolívar: "Presidente vitalicio sería usted".

San Martín: "La monarquía sería interina hasta que poco a poco el Perú se transforme en una república". Bolívar: "Mi ejército no me perdonaría que le preste para algo asi".

San Martín: "No estoy hablando con su ejército. ¿Usted cree que están preparados para gobernarse solos?"

Bolívar: "Claro no. Se soluciona con un presidente vitalicio".

San Martín: "No hay en el Perú una persona que pueda ocupar ese cargo".

Bolívar: "Usted".

San Martín: "Yo soy un general. No tengo ni pretendo tener un cargo en el gobierno. Tener los dos cargos no es bueno. Mi aspiración es la liberación definitiva, dejar organizados para que ellos puedan decidir su futuro. Usted no me va a prestar su ejército. Ya lo decidió la reunión pasada, ¿verdad?"

Bolívar: "Por qué no organiza un ejército".

San Martín: "Yo tengo uno, pero no alcanza para liberar el alto Perú. ¿Quieres que vaya pueblo por pueblo y las armas y las municiones?"

Bolívar: "Todos hemos tenido que pasar por eso". San Martín: "No me dé más vueltas. ¿Me va a prestar su ejército o no?"

Después de su encuentro con San Martín.

Bolívar: "El general decidió retirarse de la vida pública. No tiene ni pretende tener un cargo. $\mathrm{Ni}$ pretende ser el libertador de Perú".

O' Leary: Triunfamos.

Bolívar: ¿Alguna vez lo dudó?

Después de su encuentro con Bolívar. San Martín a Rosita Campuzano.

San Martín: "Se acabó. Bolívar ganó la mano. Se cree invencible. No me quiso prestar su ejército. Yo llego hasta acá. Mi ejército no dará la vida por el Perú. Bolívar quiere ser el Libertador de América". 
Tabla 7

Acontecimientos previos y la llegada de Bolívar al Perú

\begin{abstract}
Subtexto
“Recordemos rápidamente los acontecimientos previos a la llegada del Libertador. En junio de 1823, luego de estar en el poder escasamente cuatro meses, el "golpista" Riva-Agüero fue depuesto por el "golpista" Sucre quien, respaldado por sus batallones fieles colombianos, presionó al Congreso para que "exonerase" a Riva-Agüero de la presidencia y lo nombrase a él Jefe Supremo de las fuerzas militares del Perú. Pero Sucre era más que un joven militar de fortuna, era también un político en ciernes que seguía al pie de la letra las instrucciones de Bolívar. Ambos sabían que en poco tiempo su nombramiento podría ser sujeto a críticas en el Congreso.

\section{Intertexto (Episodio 43)}

Bolívar es presidente de la gran Colombia, pero está en Quito. Solicita permiso al Congreso para emprender una campaña para liberar al Perú. Le envía esta carta al vicepresidente Santander:

El presidente Riva Agüero traicionó a su patria aliándose con los realistas, por eso consideran que la única solución posible es el Ejército colombiano. Los realistas están por todos lados. Argentinos y chilenos se niegan a ayudar. Aceptar no solo es un mandato para ayudar al pueblo peruano, sino por la impetuosa necesidad de conjurar toda amenaza realista a nuestras causas patriotas.
\end{abstract} Es así como, sin renunciar a sus poderes, Sucre "delega" algunos en Torre Tagle, un limeño aristócrata, débil y manejable. Torre Tagle aceptó de agrado esas atribuciones que no eran otras que ser mensajero de los colombianos. Mientras tanto el país seguía dividido, tal como Bolívar había anhelado, pues Riva-Agüero no renunció a la presidencia y actuaba como tal desde Trujillo, respaldado por el ejército de Norte y el del Sur. Para dar mayor realce a la figura de Torre Tagle, el Congreso lo nombró presidente el 19 de agosto de 1823, aunque fuese Sucre quien siguiera gobernando interinamente. Esto ocurrió cuando de antemano se sabía que había tenido "éxito" la comisión del Congreso que fue a ver a Bolívar para "invitarle" a venir al Perú, otorgándole todo el poder político y militar según decreto del 19 de junio de 1823. Así pues, cuando Torre Tagle fue nombrado presidente, Bolívar estaba en camino a Lima. El 1 de setiembre de 1823 once días después del nombramiento de presidente de Torre Tagle, Simón Bolívar llegó a Lima siendo recibido con una febril acogida rayana en la histeria colectiva. Los pueblos oprimidos o desunidos o cobardes o mártires, siempre han esperado un Mesías que los salve. En un menor o mayor grado los limeños reunían todas esas condiciones" (Morote, 2007, p. 38).

"El entusiasmado e influenciado, o temeroso Congreso entendió correctamente que lo que quería Bolívar era más poder y lo nombró "Libertador", con autoridad política y militar en todo el territorio nacional" (Morote, 2007, p. 47).

Torre Tagle "amaba el mando no porque fuese ambicioso sino por ostentación". Basadre cuenta que "Como vana compensación por la merma que había hecho en su jerarquía, el Congreso acordó dar a Tagle una medalla con el nombre de "Restaurador de la representación soberana»" (Morote, 2007).

Torre Tagle “era una sombra del Poder (...) se tenía por el primer hombre del Perú, y así se lo hacían creer sus aduladores que le rodeaban, lo cual para su limitada capacidad era suficiente" (Morote, 2007).
Santander confabula para que el Congreso se oponga, pero pierde, gracias a la intervención del general Urdaneta y el voto del congresista Antonio Nariño. Finalmente, el Congreso de la Gran Colombia aprueba la campaña de Bolívar.

Se ve a Bolívar atravesar las cordilleras a lado de Córdova y O'Leary, mas no Sucre. Se supone que él se adelantó y está en otra parte del Perú, porque, más adelante, cuando se diseña la estrategia militar, hace una pausa y dice que le avisen cuando llegue Sucre.

A su llegada, Bolívar es recibido por Torre Tagle, presidente de la Junta de Gobierno del Perú. Él ha preparado una hacienda en las afueras de Lima para que Bolívar se asiente con su ejército. Torre Tagle le dice que las esperanzas de todo el Perú están puestas en él.

Torre Tagle se ofrece a ayudarlo en todo. Se presenta muy servil y sumiso frente a Bolívar. Va a informarle de todo a Bolívar.

Bolívar espera la ayuda de Colombia. Ha pedido $12 \mathrm{mil}$ soldados. Tiene 5 mil soldados frente al ejército realista que tiene 18 mil y están dos años en la sierra. Conocen el terreno. El gobierno de Colombia le envía apenas 500 hombres.

Cuando Bolívar le pide a Torre Tagle que aporte a la guerra, este se da cuenta de las debilidades de Bolívar y su ejército. Y busca a los realistas. Va de incógnito al cuartel de los realistas para informarle al virrey La Serna y al general Canterac de la debilidad de Bolívar. Les sugiere que es el momento de retomar Lima.

Después el ejército realista retoma Lima y Torre Tagle se esconde.

El general La Mar va al cuartel de Bolívar a informarle que Torre Tagle los traicionó y que el Congreso del Perú decidió otorgarle todos los poderes.

Sucre: "Pero si el general Bolívar ya tiene todos los poderes. Lo que necesita son hombres y dinero".

La Mar: "En este caso es distinto. Estamos hablando de nombrarlo dictador del Perú. Para que pueda legislar, ordenar y juzgar lo que él crea conveniente".

Bolívar: "Vamos a expropiar a los enemigos, la iglesia tiene que aportar, vamos a subir impuestos a los más pudientes y los indígenas se unirán al ejército. Les vamos a entregar las tierras expropiadas para que sus mujeres y sus hijos las pongan a producir. Y así también tendremos cómo alimentar al ejército. El ejército va a estar autorizado a llevarse todo". 
La Mar: “¿Cómo hacer para que los funcionarios no se roben el dinero?"

Bolívar: "Todo funcionario que se le pruebe que se roba más de diez pesos se someterá a la pena capital".

La Mar: "¿Muerto?"

Bolívar: "Muertos. El que roba al Estado va a morir. Señores, el Perú va a ser libre y hasta el último de los españoles va a tener que irse de América".

La aristocracia criolla no cree en Bolívar. Piensa que va perder y morir. Y que deben apoyar la causa realista.

\section{Tabla 8}

\section{Batalla de Junín y Ayacucho}

\begin{abstract}
Subtexto
"No sería exagerado decir que Bolívar obtuvo la independencia del Perú en 1824 a pesar de la mayor parte de los peruanos. También es justo afirmar que esa independencia no la hubiera logrado sin el apoyo de una minoría peruana que se sacrificó económicamente y físicamente, ofreciendo sus vidas y haciendas por una causa en la que estaban confiados en ganar con Bolívar o sin él" (Morote, 2007, p. 52).

"El reclutamiento de indígenas y campesinos para ir a pelear en una guerra entre sus explotadores fue inmisericorde, Bolívar decretó en el territorio norteño el reclutamiento de niños mayores de 12 años hasta hombres de 40 . Muchos de ellos fueron enviados a reemplazar las bajas de los batallones colombianos. Santa Cruz apresó a 2,000 hombres en la sierra central que incorporó a su ejército. Estos eran los que habían escapado al reclutamiento previo de los españoles" (Morote, 2007, p. 56-57).

"A todos los jefes militares Bolívar les ordena: Tomar todas las alhajas de oro y plata de las iglesias para amonedarlas y destinarlas a los gastos de la guerra; todas las piedras preciosas y cuanto tenga valor en las iglesias, sin dejar en ellas, sino lo más indispensable para el culto" (Morote, 2007, p. 57).

"Antes de cumplir el año de su llegada, Bolívar había reclutado, equipado, entrenado y levantado la moral de un ejército de 12,000 hombres, dispuesto a enfrentarse al poderoso ejército virreinal. Así, cuando el 2 de agosto de 1824 en las llanuras de Rancas próximas a Cerro de Pasco, Bolívar pasó revista al ejército patriota formado por soldados de la Gran Colombia, peruanos, argentinos y chilenos, no tuvo ninguna duda de que tenía el triunfo en sus manos. Convencido de eso lanzó su famosa proclama:
\end{abstract}

iSoldados! iVais a completar la obra más grande que el cielo ha podido encargar a los hombres: la de salvar un mundo entero de la esclavitud! iSoldados! Los enemigos que vais a destruir se jactan de catorce años de triunfos; ellos, pues, serán dignos de medir sus armas con las vuestras que han brillado en mil combates. iSoldados! El Perú y la América toda aguarda de vosotros la Paz, hija de la Victoria, y aun la Europa liberal os contempla con encanto porque la libertad del Nuevo Mundo es la esperanza del Universo. ¿La burlaréis? No. No. Vosotros sois invencibles.

Cuatro días después se dio la batalla de Junín donde la caballería de Canterac cayó derrotada. En cuatro meses más,

\section{Intertexto (Episodio 45)}

Los realistas tomaron Lima y saquearon toda la ciudad.

El ejército realista está dividido. El general Olañeta se sublevó a Canterac. Uno pretende desconocer al virrey La Serna y el otro no.

Bolívar: "Estamos listos antes de que se unan".

Bolívar apuesta un ataque sorpresa.

El discurso de Bolívar:

iSoldados!, pronto vamos a completar la obra más grande que el cielo ha podido encargarle al hombre: salvar a un mundo entero de la esclavitud!

iQue viva el general Bolivar! iQue viva la patria libre! iLibertad!

iUstedes!, van a destruir a un enemigo que se jacta de catorce años de triunfos, pero no sabe de cuántas batallas han salido victoriosas sus armas. El Perú y la América entera espera de ustedes paz y esa paz es hija de nuestra victoria. Hasta la Europa liberal nos ve con encanto porque la libertad del Nuevo Mundo es la esperanza del Universo. iLibertad! Los realistas subestimaron a Bolívar. El general Canterac fue derrotado, pese a su superioridad numérica.

Ante la desautorización de Bolívar por parte del Congreso de la Gran Colombia, designa a Sucre para que comande el ejército.

Recuperar Lima fue fácil.

Sucre le escribe a Bolívar después de la batalla de Ayacucho: Esperamos la tarde y le hicimos pensar que desistíamos. En la noche enviamos a nuestros hombres con antorchas para simular que nos retirábamos, mientras otros iban al frente. Tenemos más de 200 prisioneros. El virrey La Serna y todos los generales y mariscales. En este momento marcho hacia el Alto Perú a fin de que no quede ni un solo realista en América.

Bolívar: “En Bogotá no creo que se alegren. Pensé que antes teníamos causas comunes. No estoy seguro de la gratitud hacia lo que hemos hecho".

Bolivar hace una fiesta.

La Mar: "¿Le parece bien las personas que invitamos, general?"

Bolívar: "Sí, sí. Estoy viendo que acá cuando se hace una fiesta, sea realista o patriota, siempre son los mismos invitados". 
el 9 de diciembre de 1824, los españoles fueron derrotados en Ayacucho. El Perú quedó libre después de tres siglos de dominio español. Atrás quedó el precio por esta independencia, es decir, atrás quedaron los saqueos, los robos, los cupos de guerra, la conscripción forzada, la "política de tierra arrasada" que dejó en la miseria a una nación opulenta. Todo esto se olvidó. El triunfo que consiguió Bolívar hizo que las penas se disipasen en ese momento. El fin justificó los medios" (Morote, 2007, p. 60).
La Mar: "Esto es absolutamente cierto, aunque hay personas que definitivamente tuvieron que salir". Bolívar: “¿Quién es el señor Hart?”

La Mar: "Hart es un americano miembro prestante de la armada de su país y está invitado con dos de sus hijas".

\section{Tabla 9}

\section{La Constitución vitalicia}

\begin{tabular}{|c|c|}
\hline Subtexto & Intertexto (Episodio 46) \\
\hline $\begin{array}{l}\text { "Según estos historiadores la Constitución Vitalicia escrita por } \\
\text { Bolívar era un término medio entre la monarquía y la "república } \\
\text { jacobina" que propició la constitución liberal de } 1823 \text {, cuando a } \\
\text { todas luces lo que proponía era una monarquía absolutista } \\
\text { disfrazada de república" (Morote, 2007, p. 212). } \\
\text { "El Libertador no podía echarse atrás, el proyecto monárquico } \\
\text { de San Martín había sido rechazado abrumadoramente y el } \\
\text { mismo Bolívar se mostró en numerosas ocasiones } \\
\text { meridianamente opuesto a ello. Erguirse rey estaba totalmente } \\
\text { descartado, por ello el Libertador creó una aparente República } \\
\text { con la figura Presidente Vitalicio, quien tendría las mismas } \\
\text { atribuciones y privilegios de un rey absolutista sin ser llamado } \\
\text { tal. En otras palabras: diseñó un burdo engaño que ha durado } \\
\text { demasiados años en nuestras bibliotecas y conciencias. Uno } \\
\text { podría aventurase a afirmar que la atracción que tienen los }\end{array}$ & $\begin{array}{l}\text { En una escena se muestra a Bolívar reflexionando frente a } \\
\text { Manuelita Sáenz: "La Constitución vitalicia hecha en Perú } \\
\text { es porque el pueblo requiere orden. San Martín ya se había } \\
\text { dado cuenta. [En Guayaquil San Martín le propuso una } \\
\text { monarquía, pero Bolívar, la rechazó]. Nuestras reformas no } \\
\text { son suficientes. El resultado no es bueno. La libertad no han } \\
\text { sabido manejarla. Añoran la época en la que había un rey } \\
\text { que le decía qué hacer. Creímos que bastaban con darle la } \\
\text { libertad. No basta. San Martín se dio cuenta. La gente } \\
\text { necesita un grupo de gente que lo dirija. La Constitución de } \\
\text { Cúcuta no era real. Está basada en sueños". } \\
\text { Santander y la élite colombiana cuestionan la Constitución } \\
\text { vitalicia y defienden la de Cúcuta. Critican el poder absoluto } \\
\text { del presidente vitalicio y lo consideran semejante al de un } \\
\text { rey. }\end{array}$ \\
\hline
\end{tabular}
peruanos por un mandatario "fuerte", por el tirano, es francamente atávica, de otro modo no se explicaría tantos años de opresión militarista. En la constitución bolivariana el poder del Presidente Vitalicio sobrepasaba a la de un rey constitucional como el del Reino Unido y era más próximo al de un rey absolutista, como el rey "felón" Fernando VII que reinaba en esos tiempos" (Morote, 2007, p. 212).

\section{Tabla 10}

\section{Últimos días de Bolívar en Perú y su salida}

\section{Subtexto}

Intertexto (Episodios 46, 47, 48)

\footnotetext{
"La elección fraudulenta de Simón Bolívar como Presidente Vitalicio del Perú, así como su respectiva Constitución duró apenas 48 días. No fue, desgraciadamente, debido a las presiones de peruanos, ni a los amotinados colombianos que se levantaran en armas contra Bolívar porque habían recibido dinero de los aristócratas limeños, como supone el historiador colombiano Liévano Aguirre. Qué orgullo tendríamos en decir que fueron los mismos peruanos quienes pusieron término a la dictadura. No, los peruanos poco tuvieron que ver con el derrocamiento bolivariano" (Morote, 2007, p. 214). "Fueron las mismas tropas colombianas quienes depusieron a sus jefes en Lima, los tomaron presos, y los enviaron de regreso a su patria, dejando libre al Perú de sus opresores. Varias fueron las razones para el levantamiento en Lima de la 3 a División Colombiana, muchas de ellas de poco lustre político.

La señora de Cortázar escribe desde Lima a Elsa, su hermana que está en Inglaterra: En Lima, la gente no habla más que de Bolivary su amante. Pero lo detestan y esperan que se vaya.

Bolívar se va del Perú, porque lo han llamado para apaciguar a los rebeldes que quieren separar a Venezuela de Colombia. A la partida de Bolívar, la moral del ejército se debilita. Sufren hambre y no tienen salarios. Las promesas que les hicieron no
} 
Aunque los colombianos recibían mejores pagas que las tropas peruanas, sus salarios estaban atrasados, incluidos los premios otorgados por el Congreso a los vencedores de Ayacucho. A esto añádase el malestar creado por la diferencia astronómica entre lo que recibía la tropa y lo que ganaban sus jefes" (Morote, 2007, p. 215).

"Sin embargo, el factor desencadenante del levantamiento vino desde Colombia, el largo brazo de Santander soterradamente azuzó a las fuerzas colombianas a rebelarse en el Perú contra sus jefes, que eran en su mayoría venezolanos. Sabía muy bien Santander que, si la presidencia vitalicia de Bolívar tenía éxito en el Perú, podía extenderse a Colombia. Por el contrario, si el Perú se revelara contra Bolívar, la presencia del Libertador en Colombia se debilitaría gravemente y no podría recuperar la presidencia a la que Santander siempre aspiró. El ajedrez político fue jugado sagazmente por el vicepresidente colombiano, socavó la retaguardia del Libertador rebelando contra él a las veteranas tropas colombianas vencedoras de Junín y Ayacucho. Fue así como el 26 de enero de 1827, el coronel colombiano José Bustamante encabezó a los rebeldes que tomaron presos a los jefes venezolanos, incluyendo al fiero general Jacinto Lara, y ocuparon el Palacio de Gobierno, la Plaza de Armas y varios emplazamientos claves. Ese día el Consejo de Gobierno, salvo Pando, se encontraba con otros altos funcionarios y autoridades veraneando en el balneario de Chorrillos. José Pando, que era el único miembro del Consejo que estaba en Lima, intentó ingresar a Palacio en su calidad de ministro del Interior, pero lo único que consiguió fue ser despedido con cajas destempladas por los colombianos. Se le urgió tomar su caballo y dirigirse a Chorrillos. Los rebeldes sólo querían mantener comunicación con el Presidente del Consejo de Gobierno, general Santa Cruz, pero no con sus ministros" (Morote, 2007, p. 216).

"Una de las primeras decisiones que tomaron las tropas colombianas y el Cabildo de Lima fue deshacerse de los generales venezolanos. Fue así como a los pocos días todos ellos fueron embarcados rumbo a Colombia. La era bolivariana había llegado a su fin. No obstante, el cónsul colombiano y la fiel amante de Bolívar, Manuelita Sáenz, que se había quedado momentáneamente en Lima, complotaron e intentaron seducir a las tropas colombianas con ofertas de dinero en "cantidades muy crecidas" según un testigo de la época. Todos los esfuerzos por cambiar el rumbo de los acontecimientos no llegaron a prosperar y finalmente, el 18 de marzo de 1827, las tropas colombianas partieron del Callao para no regresar jamás" (Morote, 2007, p. 217).

"Bolívar, que se encontraba en Venezuela tratando de evitar su independencia de la Gran Colombia, comenzó a desconfiar inmediatamente del apoyo de los mandos colombianos" (Morote, 2007, p. 217). les cumplieron. Manuelita Sáenz intenta ganarse a los solados.

La familia Cortázar es la familia aristocrática que va de un bando a otro. Fueron realistas, después patriotas. A penas sale Bolívar llaman a Bustamante para poner al ejército de su lado y contra Bolívar.

El coronel colombiano Bustamante alienta al ejército contra Bolívar. La Mar está enfermo en la guarnición y sin capacidad de actuar. Finalmente, deportan a Manuelita Sáenz, al general Córdova y a muchos otros del ejército de Bolívar.

Santander está en contra de la Constitución Vitalicia y teme que Bolívar llegue a ser el presidente de toda Sudamérica. Bolívar tampoco confía en Santander.

\section{Discusión}

Bolívar, una lucha admirable tiene muchas imprecisiones geográficas, lingüísticas e históricas respecto al Perú, tales como: el lugar (se supone Rancas), donde está el ejército patriota antes de la Batalla de Junín, se encuentra en medio de una vegetación frondosa; las pampas de Junín están rodeadas de árboles; la aristocracia limeña habla con acento colombiano; el general La Mar habla con acento colombiano; Bolívar atraviesa Los Andes para llegar al Perú; el Ejército de Bolívar se asienta a 7 kilómetros de Lima, etcétera. Asimismo, presenta a un Simón Bolívar separado de la política peruana. Aparece como el general y su 
ejército que han llegado al Perú para liberarlo casi sin intervenir en el gobierno. Sin embargo, el valor de la serie, como toda serie o telenovela histórica, no está en la exactitud geográfica ni histórica, sino en la explicación y la interpretación global de los hechos. Muestra una interpretación posible apoyándose en datos recogidos por los historiadores.

Así, de la serie se desprenden las siguientes conclusiones respecto al Perú: a)Bolívar era un gran militar, pero también un político; b) Bolívar fue decisivo para la independencia del Perú; c) Bolívar independizó al Perú a pesar de los peruanos; d) Bolívar despreció la actitud acomodaticia de la clase gobernante del Perú; e) Bolívar anexó Guayaquil a Colombia y redujo el territorio peruano; f) Bolívar se impuso a San Martín en la conferencia de Guayaquil; g) Bolívar creó Bolivia con una parte del territorio del Perú; h) la clase dirigente del Perú llamó a Bolívar, lo respaldó y conspiró contra él; i) la fragilidad institucional de la República del Perú fue casi extrema, que se vio en el cambio permanente de presidentes, en la concesión de todos los poderes a Bolívar y en las medidas contra la corrupción que dio el general; j) el Perú contribuyó con soldados para que Sucre ganara la batalla de Pichincha y Bolívar independizara Quito; k) Bolívar impuso una Constitución Vitalicia, pero no duró mucho tiempo; y l) Bolívar no regresó al Perú, porque fue traicionado por sus propios oficiales colombianos.

Estas mismas conclusiones también las encontramos en el libro de Herbert Morote y se evidencian en las relaciones intertextuales halladas. También, se relacionan con otros textos de historia del Perú. Subrayamos tres de las intertextualidades más importantes: la independencia peruana, la institucionalidad del Estado peruano y la corrupción.

\section{La independencia peruana}

A la pregunta ¿la independencia del Perú fue concedida, concebida o conseguida?, la telenovela responde: fue concedida por dos extranjeros. San Martín la empezó, pero Bolívar la concluyó. En esto coincide con Herbert Morote:

La verdad es que la independencia nos fue impuesta por extranjeros. Primero, por la expedición libertadora de San Martín, y luego por el genio militar de Bolívar, ambos jefes vistos con buenos ojos por Inglaterra y ayudados por ella con eficientes súbditos reclutados por los patriotas y préstamos para financiar las campañas (Morote, 2007, p. 21).

Historiadores como Heraclio Bonilla también sostienen que la independencia del Perú fue concedida mas no obtenida, entre otras razones, porque la clase acomodada del país tenía privilegios en el sistema colonial a los que no quiso renunciar. 
Si en Buenos Aires y en Caracas la aspiración a la independencia de la burguesía criolla nació del deseo de superar su inferioridad política y alcanzar en este campo la hegemonía plena para hacerla conciliable con su poderío económico, ello no ocurrió ni podía ocurrir en el Perú. Toda la fuerza anterior de la clase hegemónica peruana, por el contrario, se nutrió de su vinculación con la metrópoli. Internamente no existieron ni las bases materiales ni los fundamentos ideológicos que impulsaran la liberación. Tal vez más bien, la esperanza de un reforzamiento de la situación colonial y lamentos por el esplendor perdido (Bonilla, 2015, p. 46).

Desde Lima se enviaron fuerzas para acabar con las juntas independentistas en lugar de apoyarlas. Se trató de sofocar todo brote rebelde, a diferencia la burguesía criolla de Venezuela y Argentina.

En el Perú, la situación fue diametralmente opuesta. No solo las juntas no se llegaron a formar, sino que desde aquí se enviaron tropas para reprimir los ensayos realizados por los criollos de La Paz y Quito para constituir tales juntas (Bonilla, 2015, p.47).

Así, Bolívar, una lucha admirable presenta la independencia del Perú y Bolivia como un hecho protagonizado por dos extranjeros y no como un logro de peruanos y bolivianos. Esto, hasta cierto punto, como se ha señalado, es compartido por varios historiadores. Sin embargo, esta posición omite referirse a los movimientos anticolonialistas realizados por mestizos e indígenas del Alto y Bajo Perú.

“En el Bajo y Alto Perú, la trayectoria anticolonial fue más nítida, y consecuente, que en el caso de la capital del virreinato" (O’Phelan, 2015, p. 212). "La postura crítica anticolonial parece haberse introducido en Lima desde fuera. Primero a través de la infiltración de los programas del sur andino, y luego teniendo por portavoces a San Martín y Bolívar" (O’Phelan, 2015, p. 212).

\section{La institucionalidad del Estado peruano}

Bolívar, una lucha admirable muestra un Estado colombiano en construcción: el presidente Bolívar delegando funciones, el vicepresidente Santander preocupado en gobernar, el Congreso, la Constitución de Cúcuta, la Casa de la Moneda, los programas de educación, entre otras instituciones. En cambio, en el Perú casi no se ve al Estado o se ve muy débil. El presidente Torre Tagle recibe a Bolívar en un cuartel acondicionado para El Libertador y se presenta siempre solícito y sumiso para informarle. Bolívar es nombrado dictador por el Congreso, pero solo se ve el momento en que se entera. Bolívar es el Presidente, pero siempre está en el cuartel, tomando decisiones bélicas. Así, la serie muestra a un Estado peruano casi inexistente. 
Esto no es ajeno a la historiografía conocida. Entre 1821 y 1830 se cambiaron de gobernante 22 veces, dos gobernantes por año, 11 personas diferentes se alternaron en el poder. Cuando Bolívar llegó gobernaba Torre Tagle. Y mientras Bolívar era el presidente, delegó sus funciones a: José Domingo de la Mar Cortázar, Hipólito Unanue Pavón y Andrés de Santa Cruz Calaumana. Esta ausencia del Estado y la sobrepresencia de Bolívar ha llevado a decir a historiadores que Bolívar dejó a un conjunto de caudillos militares que querían emularlo.

Otros pagos por nuestra independencia el año 1824 fueron: el continuo atropello a la Constitución, el mancillamiento del parlamento, la traición a la población indígena, la restauración de la esclavitud, y lo peor de todo - peor aun que la pérdida de la mitad del territorio nacionalfue el mal ejemplo de caudillaje militar que dejó un Libertador quien, a pesar de su carisma, indudable genio e inteligencia, no fue capaz de comprender que el Perú no necesitaba un modelo como él ni como el de Napoleón ni el César, sino como el de Washington o Jefferson. Por eso Bolívar al morir no dejó ni herederos ni herencia, sólo burdos imitadores y caos (Morote, 2007, p. 17).

Esta debilidad institucional caracteriza al Estado peruano aún hoy. Pese a que se ha avanzado, todavía existen muestras de la precariedad de las instituciones.

\section{La corrupción}

La telenovela Bolívar, una lucha admirable muestra a Bolívar desde un punto de vista heroico, épico: general desinteresado por él mismo y por su familia y más preocupado por la emancipación de los pueblos. Sin embargo, da pie a inferencias. Por ejemplo, cuando Bogotá le niega soldados y recursos económicos, solicita a los peruanos que "pongan su parte". Y cuando lo nombran presidente, da medidas para recaudar fondos. ¿Cómo hizo un ejército recién llegado para recaudar y manejar lo recaudado? ¿Cómo hizo un Estado peruano casi inexistente para apoyar en esa recaudación y en la administración de lo recaudado? Las respuestas se pueden inferir a partir de medidas como la pena de muerte para los corruptos dadas por el Bolívar de la telenovela. No hay pena sin delito.

Los historiadores han señalado que la corrupción es un mal congénito de la República peruana. Desde los comienzos, no se evitó ni se combatió con eficacia.

El general Simón Bolívar, cabeza de la campaña final que venció al ejército realista en el Perú, también tomó parte en las dañinas prácticas de expropiación local y abuso de autoridad. Bolívar y su dedicado ministro José Faustino Sánchez Carrión decretaron, en el periodo 1824 -1825, la confiscación de las rentas y la expropiación subsiguiente de quienes se hubiesen refugiado en la 
fortaleza del Real Felipe en el Callao, el último bastión desesperado de españoles y criollos recalcitrantes. Sánchez Carrión recibió varias propiedades como recompensa a sus fieles servicios. Bajo condiciones de extrema penuria fiscal y endeudamiento, un Congreso servil recompensó a Bolívar en 1826 con más de un millón de pesos (Quiroz, 2013, p. 105).

Los invasores que vinieron a proclamar la libertad y la independencia eran crueles, rapaces, carentes de principios e incapaces. Sus malos manejos, su despilfarro y su sed de saqueo pronto alienaron los afectos de los habitantes (Quiroz, 2013, p. 106).

Dos siglos después, la corrupción todavía es uno de los mayores problemas del Perú. Los últimos seis presidentes en la cárcel o acusados de corrupción muestran el nivel de deterioro moral e institucional.

\section{Conclusión}

Se encontraron las siguientes relaciones intertextuales: citas y alusiones. Existen semejanzas en la presentación global de Simón Bolívar en relación con el Perú; la Batalla de Pichincha; la entrada de Bolívar a las ciudades; las situaciones previas y el encuentro en Guayaquil entre Simón Bolívar y San Martín; los acontecimientos previos y la llegada de Bolívar al Perú; las batallas de Junín y Ayacucho; la Constitución vitalicia; y los últimos días de Bolívar en Perú y su salida.

La serie televisiva Bolívar, una lucha admirable reafirma la idea, compartida por muchos historiadores, que la independencia del Perú fue "concedida" por los extranjeros, por los ejércitos de San Martín y Bolívar. Omite referencias a los movimientos anticolonialistas que se desarrollaron en el Bajo y Alto Perú en el siglo XVIII y los primeros años del XIX.

\section{Referencias}

Ballón, E. (2014). El Pizarro de Beethoven. Alegorías artísticas de un emblema histórico peruano. Epojé.

Barbero, J. M. (1988). Matrices culturales de la telenovela. Estudios sobre las Culturas Contemporáneas, $2(5), 137-164$.

Berlanga, I., Arjona, J. y Merino, A. (2018). Semiótica digital en la serie El Ministerio del Tiempo. Sigma, (27), 233-262. 
Bonilla, H. y Spalding, K. (2015). La independencia en el Perú: las palabras y los hechos. En Contreras, C. y Glave, L. (Eds.), La independencia del Perú. ¿Concedida, conseguida, concebida? (pp. 39-73). Instituto de Estudios Peruanos.

Capello, G. (2019). Prácticas narrativas en las ficciones seriadas para la web. Una mirada a la producción de cuatro países en Sudamérica. Comunicación y Sociedad, e7122, 1-22. https://doi.org/10.32870/cys.v2019i0.7122

Charlois, A. y Orozco, G. (2010). Ficción televisiva e historia: una perspectiva desde la telenovela histórica mexicana. Entretejidos comunicacionales. Aproximaciones a objetos y campos de la comunicación. Universidad de Guadalajara.

Eco, U. (1992). Los límites de la interpretación. Lumen.

Eco, U. (2012). Sobre literatura. Sudamericana.

Eco, U. (2013a). Lector in fabula: la cooperación interpretativa en el texto narrativo. Sudamericana.

Eco, U. (2013b). Apocalípticos e integrados. Sudamericana.

Ferrés, J. y Piscitelli (2012). La competencia mediática: propuesta articulada de dimensiones e indicadores. Comunicar, 19(38), 75-82. https://doi.org/10.3916/C38-2012-02-08

Fontanille, J. (2012). Semiótica y literatura: Ensayos de método. Fondo Editorial de la Universidad de Lima. García, N. (1995). Consumidores y ciudadanos. Conflictos multiculturales de la globalización. Grijalbo.

García, N. (2010). La sociedad sin relato. Antropología y estética de la inminencia. Katz Editores.

Genette, G. (1989). Palimsestos. La literatura en segundo grado. Taurus.

Gómez, A. (2019). Hacia una concepción compleja de la serialización televisiva en Latinoamérica: un análisis semiótico de Luis Miguel, la serie. Dixit, 30.

Jiménez, G. y García, M. (2012). La intertextualidad en televisión: cine y publicidad. Razón y Palabra, (79). https://www.redalyc.org/pdf/1995/199524411027.pdf

Jiménez, G. y Elías, R. (2013). Cine y publicidad. La intertextualidad en las campañas de Volkswagen. Arte, Individuo y Sociedad, 25(1), 153-167.

López, P. (2007). La intertextualidad como característica esencial del discurso publicitario. Círculo de Lingüística Aplicada a la Comunicación, (30), 45-67.

Martínez, J. (2001). La intertextualidad literaria. Base teórica y práctica textual. Ediciones Cátedra.

Morote, H. (2007). Bolívar, libertador y enemigo número 1 del Perú. Herbert Morote. 
O’Phelan, S. (2015). El mito de la "independencia concedida": los programas políticos del siglo XVIII y del temprano XIX en el Perú y el Alto Perú, 1730-1814. En Contreras, C. y Glave, L. (Eds.), La independencia del Perú. ¿Concedida, conseguida, concebida? (pp. 209-245). Instituto de Estudios Peruanos.

Orozco, G. (2018). La múltiple audienciación de las sociedades contemporáneas: desafíos para su investigación. Anuario Electrónico de Estudios en Comunicación Social "Disertaciones", 11(1), 13-25. Doi: http://dx.doi.org/10.12804/revistas.urosario.edu.co/disertaciones/a.6274

Orozco, G. y Miller, T. (2017). La televisión más allá de sí misma en América Latina. Comunicación y Sociedad, (30), 107-127. http://www.scielo.org.mx/pdf/comso/n30/0188-252X-comso-3000107.pdf

Padilla, N. (19 de setiembre de 2019). "Escribir 'Bolívar' fue mi campaña libertadora": Juana Uribe. El Espectador. https://www.elespectador.com/noticias/cultura/escribir-bolivar-fue-mi-campanalibertadora-juana-uribe/

Quintero, I. (19 de julio de 2019). Sobre la serie "Bolívar" de Netflix: es cuento, no es historia. Prodavinci. https://prodavinci.com/sobre-la-serie-bolivar-de-netflix-es-cuento-no-es-historia/

Quiroz, A. (2013). Historia de la corrupción en el Perú. Instituto de Estudios Peruanos, segunda edición.

Rincón, O. (2008). La telenovela: un formato antropófago. Revista Latinoamericana de Comunicación Chasqui, (104), 48-51.

Serna-Rodrigo, Rocío (2020). El papel del intertexto en el videojuego. Una partida, mil y una historias. Ámbitos, Revista Internacional de Comunicación, (50), 145-158. https://orcid.org/0000-0003-3771$742 X$

White, H. (1992). Metahistoria. La imaginación histórica en la Europa del siglo XIX. Fondo de Cultura Económica.

Zeccheto, V. (2010). La danza de los signos. Nociones de semiótica general. La Crujía Ediciones.

Fuentes de financiamiento

Autofinanciado.

Conflictos de interés

Ninguno.

Correspondencia

mcastillo@lamolina.edu.pe 